\title{
Combining metal oxide affinity chromatography (MOAC) and selective mass spectrometry for robust identification of in vivo protein phosphorylation sites Florian Wolschin and Wolfram Weckwerth*
}

\author{
Address: Max Planck Institute of Molecular Plant Physiology, 14424 Potsdam, Germany \\ Email: Florian Wolschin - wolschin@mpimp-golm.mpg.de; Wolfram Weckwerth* - weckwerth@mpimp-golm.mpg.de \\ * Corresponding author
}

Published: 0I November 2005

Plant Methods 2005, I:9 doi:10.1 186/1746-48II-I-9

This article is available from: http://www.plantmethods.com/content/I/I/9

(C) 2005 Wolschin and PWeckwerth; licensee BioMed Central Ltd.

This is an Open Access article distributed under the terms of the Creative Commons Attribution License (http://creativecommons.org/licenses/by/2.0), which permits unrestricted use, distribution, and reproduction in any medium, provided the original work is properly cited.

\begin{abstract}
Background: Protein phosphorylation is accepted as a major regulatory pathway in plants. More than 1000 protein kinases are predicted in the Arabidopsis proteome, however, only a few studies look systematically for in vivo protein phosphorylation sites. Owing to the low stoichiometry and low abundance of phosphorylated proteins, phosphorylation site identification using mass spectrometry imposes difficulties. Moreover, the often observed poor quality of mass spectra derived from phosphopeptides results frequently in uncertain database hits. Thus, several lines of evidence have to be combined for a precise phosphorylation site identification strategy.

Results: Here, a strategy is presented that combines enrichment of phosphoproteins using a technique termed metaloxide affinity chromatography (MOAC) and selective ion trap mass spectrometry. The complete approach involves (i) enrichment of proteins with low phosphorylation stoichiometry out of complex mixtures using MOAC, (ii) gel separation and detection of phosphorylation using specific fluorescence staining (confirmation of enrichment), (iii) identification of phosphoprotein candidates out of the SDS-PAGE using liquid chromatography coupled to mass spectrometry, and (iv) identification of phosphorylation sites of these enriched proteins using automatic detection of $\mathrm{H}_{3} \mathrm{PO}_{4}$ neutral loss peaks and data-dependent $\mathrm{MS}^{3}$-fragmentation of the corresponding $\mathrm{MS}^{2}$-fragment. The utility of this approach is demonstrated by the identification of phosphorylation sites in Arabidopsis thaliana seed proteins. Regulatory importance of the identified sites is indicated by conservation of the detected sites in gene families such as ribosomal proteins and sterol dehydrogenases. To demonstrate further the wide applicability of MOAC, phosphoproteins were enriched from Chlamydomonas reinhardtii cell cultures.
\end{abstract}

Conclusion: $A$ novel phosphoprotein enrichment procedure MOAC was applied to seed proteins of $A$. thaliana and to proteins extracted from $C$. reinhardtii. Thus, the method can easily be adapted to suit the sample of interest since it is inexpensive and the components needed are widely available. Reproducibility of the approach was tested by monitoring phosphorylation sites on specific proteins from seeds and $C$. reinhardtii in duplicate experiments. The whole process is proposed as a strategy adaptable to other plant tissues providing high confidence in the identification of phosphoproteins and their corresponding phosphorylation sites. 


\section{Background}

The proteome of different developmental stages of any kind of organism reflects more directly than the genome or the transcriptome the metabolic specialisation for the actual developmental state. In plants several studies on the proteome of different developmental stages have been conducted [1]. Seed dormancy plays a crucial role in the life cycle of plants and its proteome reflects the metabolic processes during this important developmental period. However, investigation on posttranslational modifications of the proteins gives an even more detailed view on the complex nature of seed metabolism. Protein phosphorylation has been widely described as a major regulatory protein posttranslational modification influencing many important processes in living cells [2-4]. Thus, measuring protein phosphorylation is essential to reveal regulatory and signal pathways. However, the study of protein phosphorylation confronts the researcher with several hurdles.

A complicating fact is that many proteins are not only phosphorylated at one site, but on multiple sites and that each modification seems to have different regulatory functions $[5,6]$. Therefore, detection of protein phosphorylation and identification of phosphorylation sites are needed for the understanding of protein regulation.

Traditionally, phosphorylation is detected by specific antibodies and/or by incorporating radioactive [32P]orthophosphate into proteins. However, while immunolabelling is often unspecific, incorporation experiments using radioactivity might result in artificial phosphorylation events and impose waste disposal problems. Only recently has it become possible to reliably detect protein phosphorylation by resolving the proteins of interest on a gel and submitting the gel to fluorescent phosphate specific dyes followed by a staining of total protein [7-11].

The low abundance of phosphoproteins and the accurate identification of the specific phosphorylation sites, however, still impose problems.

Because of their sensitivity and resolving power, selective enrichment of phosphorylated peptides/proteins and liquid chromatography coupled to mass spectrometry (LCMS) based methods are now widely used for phosphorylation site identification (for review see $[4,12,13]$ ).

The low abundance of phosphorylated peptides can be circumvented in part by enrichment of the phosphopeptides with IMAC (Immobilised metal affinity chromatography) after tryptic digestion of phosphoproteins. While numerous publications exist describing the enrichment of phosphopeptides from animal sources considerably less studies have been published for plant tissue (for review see [14]). These broad range studies focus for example on thylakoid proteins and plasma membrane proteins of $A$. thaliana $[15,16]$ or on the moss Physcomitrella patens [17].

However, relying on just one peptide for protein identification (as is commonly done after phosphopeptide enrichment) is prone to the identification of false positives. What is more, peptides phosphorylated on serines or threonines tend to loose their phosphate group during the fragmentation process in the mass spectrometer thus further complicating correct assignment. This drawback can be circumvented by the enrichment of complete phosphoproteins since this approach leads to the identification of several peptides per protein and therefore enhances the reliability of protein identification.

Recently, we reported a novel method for the enrichment of phosphorylated proteins out of complex mixtures termed MOAC (metal oxide affinity chromatography) [18]. This method adds another tool to the repertoire of methods for the identification of phosphorylated proteins and might help to overcome some of the specificity problems associated with IMAC. In this initial study we showed that MOAC can be used to enrich phosphorylated proteins from plant leaf tissue [18].

In the present study we use MOAC for the enrichment of phosphorylated proteins from A. thaliana seeds and for proteins from C. reinhardtii cell cultures and show that the method is suitable and reproducible for different kinds of samples.

However, for the identification of the exact sites of phosphorylation further steps are necessary. As mentioned above the ionization efficiency and the quality of a phosphopeptide spectra is sometimes not good enough for reliable identification and even more difficult is the determination of the exact phosphorylation site. To circumvent these problems phosphate groups can be replaced by beta-elimination and Michael addition with more stable residues thereby increasing the ionization efficiency and improving the fragmentation behaviour [5,19-23]. Yet, these approaches sometimes result in unwanted side reactions and are difficult to perform on complex mixtures. Another promising method is the analysis of peptide sequences by electron transfer dissociation [24] but this requires sophisticated modification of the mass spectrometer not yet widely available.

The approach we employed to identify phosphorylation sites makes use of the neutral loss of $\mathrm{H}_{3} \mathrm{PO}_{4}$ during $\mathrm{MS}^{2}$ fragmentation. The dominant neutral loss peak observed in many $\mathrm{MS}^{2}$ spectra derived from serine/threonine phosphorylated peptides [25] is routinely broken down in an additional $\mathrm{MS}^{3}$ step and putative phosphopeptides are 


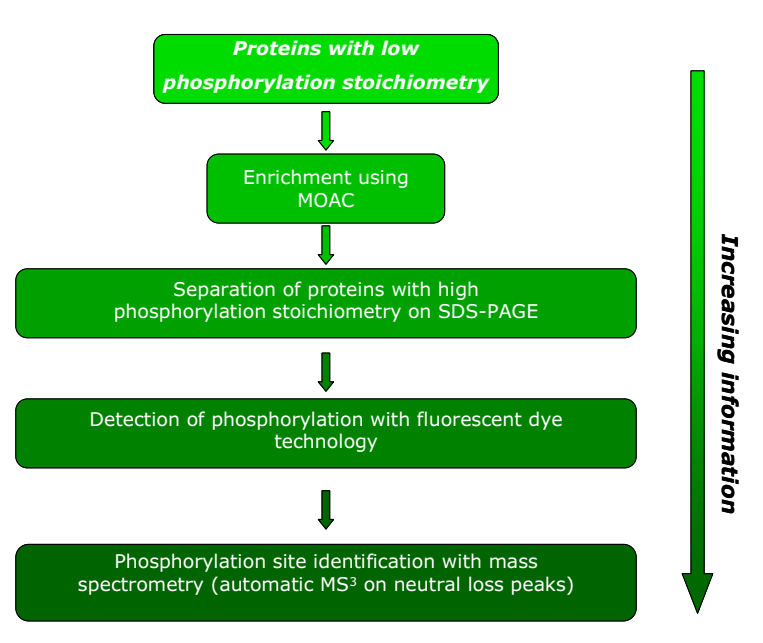

Figure I

Proposed strategy for robust identification of serine/threonine phosphorylation in plants. In case of low stoichiometry as for the in vivo situation enrichment of phosphoproteins is necessary. To cope with this a novel enrichment procedure called metaloxide affinity chromatography (MOAC) is used in the strategy [18]. The whole approach is applicable to identify phosphorylation sites out of complex samples. The library of in vivo sites may be used for screening of protein phosphorylation dynamics using triple-quadruple mass spectrometry [6].

automatically detected in a single LC/MS run [26]. The resulting $\mathrm{MS}^{3}$ spectra are often informative enough to identify the correct peptide and the phosphorylation site in a database search. However, considering the information of both $\mathrm{MS}^{2}$ and $\mathrm{MS}^{3}$ data is sometimes necessary to obtain unambiguous identification $[27,28]$.

In the present work we combine the MOAC enrichment of phosphoproteins and selective mass spectrometry for a detailed study of protein phosphorylation. Phosphorylation site identification is demonstrated for enriched seed proteins and is achieved using data-dependent $\mathrm{MS}^{2}$ as well as neutral-loss triggered $\mathrm{MS}^{3}$ fragmentation on a linear ion trap mass spectrometer. The proposed strategy is suitable to identify putative phosphoprotein candidates with high sequence coverage and at the same time it allows identification of corresponding protein phosphorylation sites. To avoid false positive identification of phosphorylation sites only hits with congruent $\mathrm{MS}^{2}$ and $\mathrm{MS}^{3}$ spectra were considered in this study. Careful validation of the data led to the identification of 16 phosphorylation sites in nine seed proteins, some of them known to be phosphorylated also in the mammalian system such as ribosomal proteins. A comparison with microarraydata showed that these proteins are mainly seed specific.

\section{Results \\ General strategy for the identification of serine/threonine phosphorylation in plants}

An overview on the general strategy for the identification of serine / threonine phosphorylation in plants is shown in Figure 1. The strategy includes enrichment of phosphoproteins using MOAC, phosphorylation detection using fluorescent dye technology, and determination of the phosphorylation site with neutral loss driven $\mathrm{MS}^{3}$. Most important, each step of the procedure gives further confidence for a robust identification of phosphoproteins and phosphorylation sites. For a detailed description see the following sections.

\section{MOAC enrichment of phosphoproteins}

Proteins were extracted with phenol and enriched for phosphoproteins using metaloxide affinity chromatography (MOAC) [18]. Proteins were separated using SDSPAGE and visualised with a phosphate-specific stain followed by staining with coomassie R-250 (Figure 1). Similar amounts of total protein from samples taken before and after MOAC (Figure 2B) are accompanied by strong differences in the phosphostain signal indicating clear enrichment of phosphoproteins out of the complex sample (Figure 2A). Bands corresponding to enriched seed proteins with a strong signal in the phosphostain were excised, digested with trypsin, and analysed by mass spectrometry (see below).

\section{Identification of in vivo phosphorylation sites in A. thaliana seed proteins}

Following the proposed strategy (see Figure 1) we identified after careful validation 16 phosphorylation sites in 9 proteins using the combined information of $\mathrm{MS}^{2}$ and $\mathrm{MS}^{3}$ data. The advantage of using the combined data is exemplified by the $\mathrm{MS}^{2}$ and $\mathrm{MS}^{3}$ spectra in Figure 3. In the first $\mathrm{MS}^{2}$ fragmentation step a very intense fragment ion stemming from a dominant neutral loss of phosphoric acid is seen. This spectrum alone is often not suitable for database search. On the other hand it is a distinct indication for a phosphopeptide. The dominant neutral loss fragment triggers in a second scan event an $\mathrm{MS}^{3}$ fragmentation step. The combination of $\mathrm{MS}^{2}$ and $\mathrm{MS}^{3}$ leads to the clear phosphorylation site identification with increased confidence based on the observed neutral loss of phosphoric acid $[27,28]$. A further level of confidence is provided by the combination of protein identification (see Figure 1 and protein sequence coverage in table 1) and the corresponding protein phosphorylation site in one LC/MS analysis. This information is missing in strategies where only phosphopeptides are enriched and protein identification is based solely on the detection of one phosphopeptide. The phosphorylation sites are shown in Table 1. The sites of the two ribosomal proteins are known to be phosphorylated in mouse [29]. For some of the proteins 

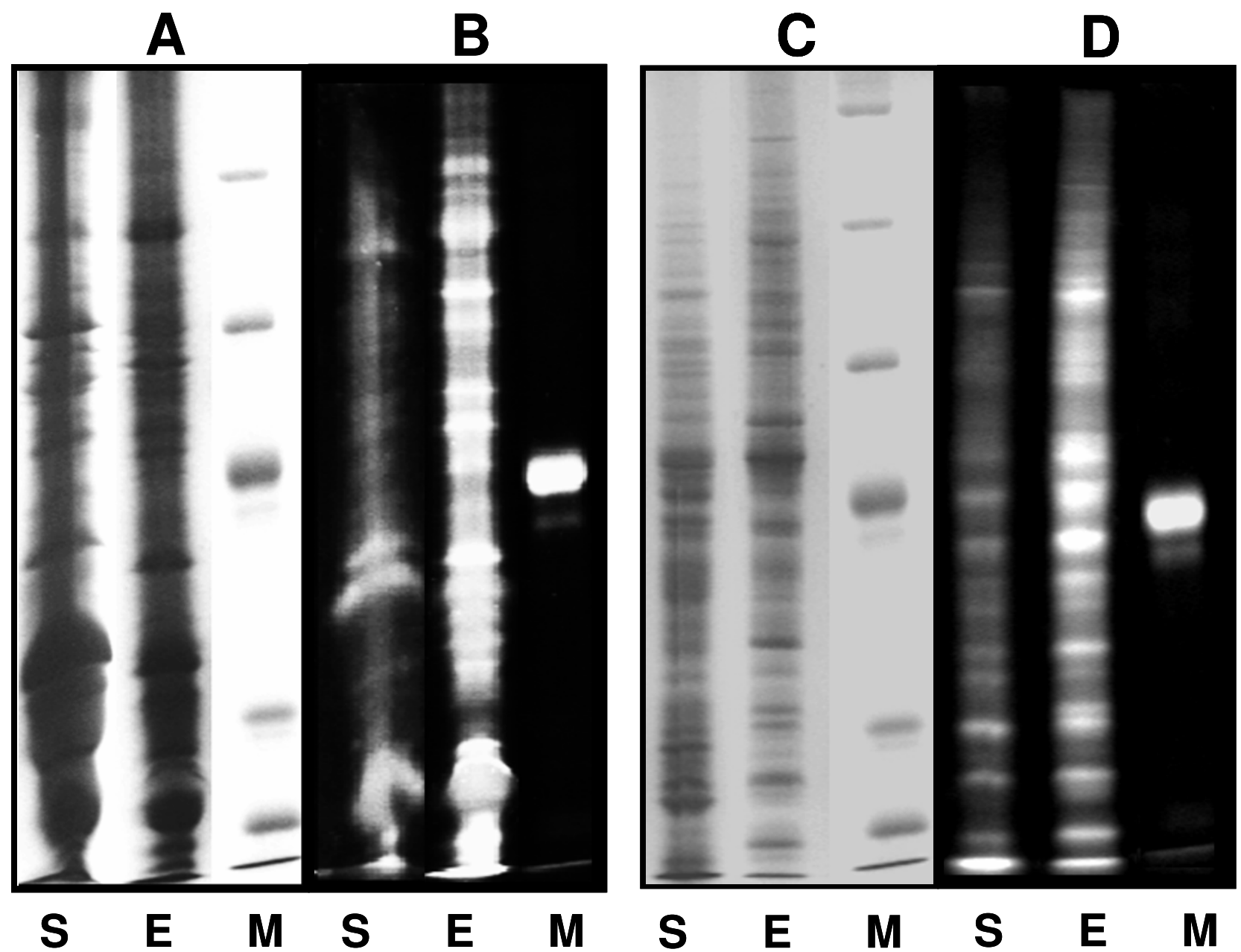

Figure 2

A. thaliana seed proteins and C. reinhardtii proteins before and after MOAC. M: marker S: sample (before MOAC) E: eluate (after MOAC); A: A. thaliana seed proteins, Coomassiestaining; B: A. thaliana seed proteins, Phosphostaining. C: $C$. reinhardtii proteins, Coomassiestaining; D: C. reinhardtii proteins, Phosphostaining. The labelled marker protein in the phosphostain is the phosphorylated protein Ovalbumin.

identified after MOAC, MS 2 data suggested phosphorylation but $\mathrm{MS}^{3}$ data were lacking. All these ambiguous results were not included in the table. The analysis of gene expression data revealed that five of the identified proteins are apparently seed specific (table 1 ). Notably, phosphorylation is most probably not confunded with osulfonation in these experiments since sulfated peptides exhibit the characteristic loss of $80 \mathrm{Da}$ instead of $98 \mathrm{Da}$ during collision induced dissociation [30], which does not lead to the triggering of an $\mathrm{MS}^{3}$ spectrum.

\section{Reproducibility of the method}

The enrichment process was repeated using A. thaliana leaf and C. reinhardtii proteins. Similar patterns were observed in SDS PAGE analysis combined with phosphoand coomassiestaining (data not shown). Two prominent bands, one of the enriched seed sample at about $65 \mathrm{kDa}$ (corresponding to the mw of the protein with the highest number of phosphorylation sites identified in the first experiment), and one of the enriched C. reinhardtii sample (in duplicate) at about $56 \mathrm{kDa}$, were selected for testing the reproducibility of phosphorylation site identification. With the seed protein we tested analytical reproducibility after storage of the sample for 1 month (see table 2). Reproducibility of the whole procedure including MOAC enrichment is demonstrated by the repeated identification of phosphorylation sites in the 56 $\mathrm{kDa}$ C. reinhardtii phosphoprotein (table 2).

\section{Phosphorylation of sterol dehydrogenase}

One phosphorylation site was identified as serine 95 in an isoform of the A. thaliana short chain sterol dehydroge- 

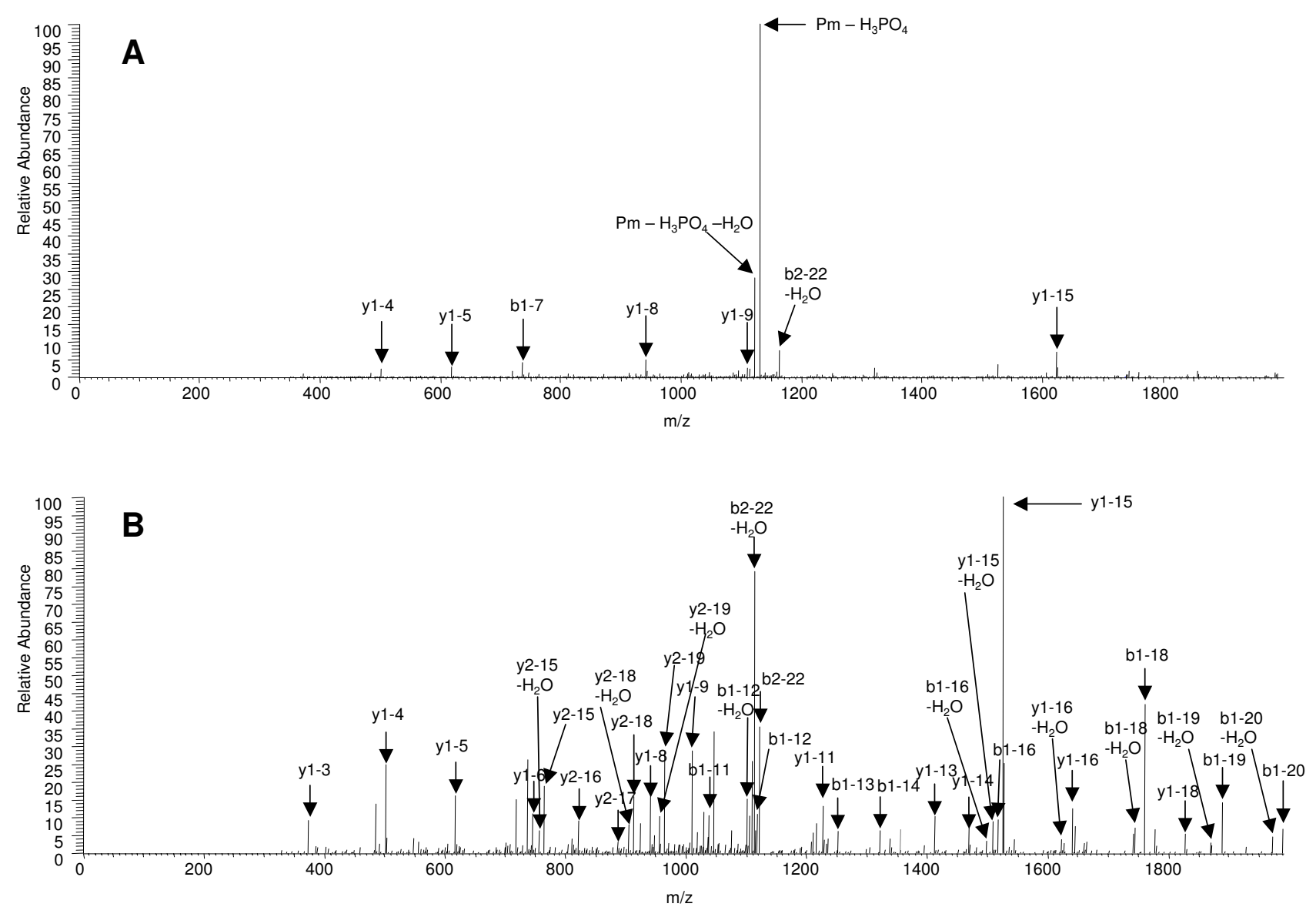

\section{Figure 3}

$M^{2}$ spectrum and the cognate neutral loss $\mathrm{MS}^{3}$ spectrum of the phosphopeptide LGYTGENGGGQSEPSPVKDETPR exemplifying the additional sequence information gained of an $M^{2}$ spectrum compared to a MS 3 spectrum. A: MS2 spectrum (Xcorr: 2.424); $\mathrm{B}: \mathrm{MS}^{3}$ spectrum (Xcorr: 3.248). Exact localisation of the phosphorylation site is only possible with the $\mathrm{MS}^{3}$ spectrum in this case. Only ions above the noise signal were annotated.

nases gene family. We aligned protein sequences belonging to the same family from A. thaliana (At) and Sesamum indicum ( $\mathrm{Si}$ ) (Figure 4). Shown is the region surrounding the phosphorylation site. The region of interest is part of a proposed NADP+ binding domain [31] and displays high homology. The serine phosphorylation site is conserved in 6 out of 8 sequences. The two remaining sequences (At4 and Si1) show no serine at the site of interest and might belong to a separate group.

\section{Discussion}

The approach described in this work is suitable to reliably identify and routinely screen for serine/threonine phosphorylation in plant proteins. Several lines of evidence are integrated into the strategy thus making unambiguous identification of protein phosphorylation possible: (i)
Enrichment for phosphoproteins based on the affinity of phosphate to MOAC, (ii) a specific phosphostain reveals phosphorylation of the proteins and confirms enrichment, (iii) gel separation of the proteins helps to guarantee high confidence in protein identification, and (iv) a highly selective method based on mass spectrometry specific for phosphorylation is used for site identification.

Phosphorylated proteins are enriched by MOAC, a method that can be easily adapted to suit the sample of interest since it is inexpensive and the components needed are widely available. For demonstration MOAC phosphoprotein enrichment was applied to A. thaliana leaf proteins [18], A. thaliana seed material and Chlamydomonas reinhardtii cell cultures (this study, Figure 2). 
Table I: Identified phosphorylation sites in seed proteins. Gene expression data were derived from a previous study [38].

\begin{tabular}{|c|c|c|c|c|}
\hline Accession $\mathrm{nr}$. & Description & Protein sequence coverage & $\begin{array}{l}\text { Site of phosphorylation (designated as } \\
\text { "p") }\end{array}$ & $\begin{array}{l}\text { Seed specific } \\
\text { expression }\end{array}$ \\
\hline At5g52300.1 & $\begin{array}{l}\text { low-temperature-responsive } 65 \mathrm{kD} \\
\text { protein (LTI65)/desiccation-responsive } \\
\text { protein 29B (RD29B) }\end{array}$ & $65.8 \%\left(M_{r} 6597 \mathrm{IDa}\right)$ & $\begin{array}{l}\text { MKVTDEPSPDQKSR } \\
\text { ESDINKNPSPARFGGESK } \\
\text { LPLSGGGPSGVKETQQGEEK } \\
\text { LGYTGENGGGQSEPSPVKDETPR } \\
\text { GAVTSWLGGKPKPSPR } \\
\text { EAHQEPLNPTPVSLLSATEDVTR }\end{array}$ & + \\
\hline At3gl2960.I & $\begin{array}{l}\text { expressed protein similar to seed } \\
\text { maturation protein from [Glycine max] }\end{array}$ & $93 \%\left(M_{r} 9464 \mathrm{Da}\right)$ & DIKDIKGTRTDDPSPR.- & + \\
\hline Atlg0I 100.1 & $\begin{array}{l}\text { 60S acidic ribosomal protein } \mathrm{PI} \\
\text { (RPPIA) }\end{array}$ & $81.2 \%\left(M_{r} 11162 \mathrm{Da}\right)$ & KKDEPAEEPSDGDLGFGLFD.- & - \\
\hline At2g27710.I & $\begin{array}{l}\text { 60S acidic ribosomal protein P2 } \\
\text { (RPP2B) }\end{array}$ & $87 \%\left(M_{r} \mid I 444 \mathrm{Da}\right)$ & KEEKEEPSDDDMGFSLFE.- & - \\
\hline At5g40420.1 & glycine-rich protein/oleosin & $42.2 \%\left(M_{r} 21279 \mathrm{Da}\right)$ & HFQFQPSPYEGGR & + \\
\hline Atlg07985.I & Expressed protein & $46.5 \%\left(M_{r} 16461 \mathrm{Da}\right)$ & KLVDKVVGSSSPTNIHPSK & \\
\hline At5g50600.1 & $\begin{array}{l}\text { short-chain dehydrogenase/reductase } \\
\text { (SDR) family protein similar to sterol- } \\
\text { binding dehydrogenase steroleosin } \\
\text { from [Sesamum indicum] }\end{array}$ & $61 \%\left(M_{r} 39087 \mathrm{Da}\right)$ & $\begin{array}{l}\text { STLYPESIRTPEIKPSD.- } \\
\text { ELGPSPNVVTVHADVSKPDDCRR }\end{array}$ & + \\
\hline At $\lg 29350.1$ & expressed protein & $14.6 \%\left(M_{r} 90879 \mathrm{Da}\right)$ & SGPSTHFSSTDSGNFQGK & No data \\
\hline At4g25580.1 & $\begin{array}{l}\text { stress-responsive protein-related } \\
\text { contains weak similarity to Low- } \\
\text { temperature-induced } 65 \mathrm{kDa} \text { protein }\end{array}$ & $57.8 \%\left(M_{r} 66520 \mathrm{Da}\right)$ & $\begin{array}{l}\text { RGAPTLTPHNTPVSLLPSATEDVTR } \\
\text { GAPTLPTPHNTPVSLLSATEDVTR }\end{array}$ & + \\
\hline
\end{tabular}

The following staining with a phosphospecific fluorescent dye is a quick and easy to use method to detect protein phosphorylation and its changes on gels. However, mass spectrometry-based site identification leads to more detailed information about site specific regulation. This holds especially true for proteins phosphorylated at multiple sites [5,6]. While it is not possible with the fluorescent stain to define if a protein is singly or multiply phosphorylated and on which amino acid the phosphate moiety is located, this can be done by mass spectrometry [32]. Consequently, enriched proteins are digested and the peptides are analysed in experiments in which an additional fragmentation event $\left(\mathrm{MS}^{3}\right)$ is triggered when a peptide looses phosphoric acid during the first fragmentation step $\left(\mathrm{MS}^{2}\right)$. The combined information of $\mathrm{MS}^{2}$ and $\mathrm{MS}^{3}$ data is then used to obtain high quality data about the peptide sequence and its phosphorylation site (see also Figure $3 \mathrm{~A}$ and $3 \mathrm{~B}$ ).

Since this is a proof of concept study we did not aim at identifying all phosphorylation sites present in the enriched fraction but at setting up a robust and convenient workflow for the analysis of in vivo protein phosphorylation in plants. The major drawback of the method in its current state is that preferably phosphorylation sites of high abundant phosphoproteins are detected and that often the protein can be assigned reliably but data on the phosphopeptides are lacking. However, this might be circumvented by separating complex mixtures using established chromatography prior to MOAC and/or by coupling a phosphopeptide enrichment step to the pro- tein enrichment. Another problem could be dephosphorylation occurring during or prior to gel separation or during sample storage. This might also explain differences in the reproducibility test. Nevertheless, most of the tested sites could be reproducibly found in a second experiment thus reconfirming the robustness of the method. However, if the sample amount is not limiting separation and digestion after enrichment might also be performed in solution without SDS-PAGE. This, of course would lead to a missing confirmation step in the strategy.

Albeit the phosphorylation of A. thaliana seed proteins probably plays a crucial role in seed development and dormancy $[33,34]$, to our knowledge this is the first time a broad approach has been used to identify phosphorylation sites in seed proteins. In more than half of the identified seed derived phosphopeptides (9 out of 16) the identified phosphorylation sites are directly neighboured by a proline. Additionally, in three peptides the sites are located adjacent to aspartic acid residues. This could be due to enhanced cleavage at proline and aspartic acid residues during the fragmentation process in the mass spectrometer which has been described before [35]. Interestingly, we did find dominant neutral loss in the respective $\mathrm{MS}^{2}$ spectra, even though it was reported recently that proline and aspartic acid containing phosphopeptides exhibit a less pronounced neutral loss of $\mathrm{H}_{3} \mathrm{PO}_{4}$ during fragmentation in a Q-Tof mass spectrometer [36]. This apparent difference might be explained by the different instrument types used in the studies or by the special nature of the investigated phosphopeptides. Both 
Table 2: Reproducibility test of phosphorylation site identification. +: detected; -: not detected.

\begin{tabular}{|c|c|c|c|c|}
\hline Protein & \multicolumn{2}{|c|}{ At5g52300.I low-temperature-responsive $65 \mathrm{kD}$ protein } & \multicolumn{2}{|c|}{ jgi code 153417 putative protein } \\
\hline $\mathrm{Mw}[\mathrm{Da}]$ & \multicolumn{2}{|c|}{65971} & \multicolumn{2}{|c|}{56515} \\
\hline Experiment & 1 & 2 & I & 2 \\
\hline Sequence coverage [\%] & 65.8 & 67.5 & 29. 1 & 28.0 \\
\hline Peptide I & GAVTSWLGGKPKPSPR & + & KLESAAPTVAER & + \\
\hline Peptide 2 & LGYTGENGGGQSEPSPVKDETPR & + & VAVAPPSRPGPSGK & + \\
\hline Peptide 3 & LPLSGGGPSGVKETQQGEEK & + & SGPSAKVAVAPSR & - \\
\hline Peptide 4 & EAHQEPLNPTPVSLLSATEDVTR & + & & \\
\hline Peptide 5 & ESDINKNPSPARFGGESK & - & & \\
\hline Peptide 6 & MKVTDEPSPDQKSR & - & & \\
\hline
\end{tabular}

serine-proline (SP) and serine-aspartate (SD,E) containing phosphorylation sites are postulated as putative kinase substrates [15]; SP is a MAP-kinase motif which coincides with the importance of MAP-kinases in cellular processes [37] (see also http://www.neb.com/nebecomm/ tech reference/protein tools/

protein kinase substrate recognition.asp). A majority of the identified phosphoproteins appear to be seed specific since their expression is reported to be highly dominant if not exclusively expressed during this developmental stage (see table 1 and [38]).

Multisite phosphorylation seems to be quite common as indicated by the fact that more than one phosphorylation site was found in 3 of the 9 proteins. The sites identified on the two ribosomal proteins are the same c-terminal sites identified in mouse [29] thus adding another evidence for the conservation of phosphorylation sites throughout different species [39]. Phosphorylation of these ribosomal P-proteins at their c-terminal end has also been proposed for Saccharomyces cerevisiaea, Rattus norvegicus, Trypanosoma cruzei, and Zea mays [40]. It has been shown that phosphorylation of these proteins leads to accelerated degradation in yeast [41] and this might also hold true for A. thaliana. Interestingly, another two of the identified phosphopeptides, belonging to proteins otherwise unrelated to the ribosomal P-proteins were also found to be phosphorylated at their c-terminal end indicating either the accessibility of c-terminal phosphopeptides for enrichment, digestion and detection or a general pattern, putatively for protein degradation.

The identification of a phosphorylated protein with homology to a short chain sterol dehydrogenase (Sop2) seems to be especially interesting for seed development. These proteins are thought to play a vital role in plant signal transduction elicited by sterols $[31,42]$ and therefore their phosphorylation/dephosphorylation might have large implications on seed development. Serine 95 in the peptide ELGPSPNVVTVHADVSKPDDCRR derived from Sop2 (which we showed to be phosphorylated in A. thaliana) is highly conserved in five out of six homologues in A. thaliana as well as in one out of two homologues in Sesamum indicum (see Figure 4). It is located in the NADP+ binding domain of the protein [31] and might be important for enzyme specificity and selectivity.

\section{Methods \\ Chemicals}

All chemicals were from Sigma (München, Germany). The aluminium hydroxide was purchased as aluminium hydroxide hydrate (ordering nr. A-1577; Sigma).

\section{Seeds}

A. thaliana (ecotype Columbia) seeds were taken from an in-house seed stock.

\section{Chlamydomonas reinhardtii culture}

C. reinhardtii (wildtype CC-125) was grown for 7 days in 16/8 hour light/dark regime in liquid culture containing TAP Medium [43]. Cells were harvested in the light period and centrifuged for $10 \mathrm{~min}$ at $4000 \mathrm{rpm}$. The supernatant was discarded and the Pellet was used for the extraction of proteins.

\section{Denatured protein extraction from A. thaliana seeds and C. reinhardtii}

A. thaliana seed proteins and C. reinhardtii proteins were extracted by adding a mixture of three volumes buffer-saturated phenol $(15 \mathrm{ml})$ and one volume $50 \mathrm{mM}$ Hepes$\mathrm{KOH}$, pH 7.2 containing 1\% $\beta$-mercaptoethanol, $40 \%$ sucrose, and $40 \mathrm{mM} \mathrm{NaF}$ ( $5 \mathrm{ml}$ ) to $2 \mathrm{~g}$ of seed material ground in liquid nitrogen or to a pellet derived from 100 $\mathrm{ml}$ of $\mathrm{C}$. reinhardtii culture, respectively. After mixing for 20 minutes at $4{ }^{\circ} \mathrm{C}$, protein was precipitated out of the phenol phase with five volumes ice-cold acetone over night at $-20^{\circ} \mathrm{C}$. The pellet was washed twice with $100 \%$ ice-cold methanol and air dried for $15 \mathrm{~min}$. 
Si2 gi|16033752| IGESLAYEYAKRGACLVLAARRERSLQEVAERARDLGSPDVVVVRADVSKAEDCRKVVDQ 118 At1 gi $118423187 \mid$ IGEQLAYEYACRGACLALTARRKNRLEEVAE IARELG PNVVTVHADVSKPDDCRRIVDD 118

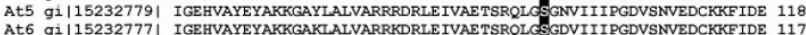
At3 gi 15241203 | IGEHLAYEYARRGAYTTIVARRBRDRLIVVADRCRKLGSPDVAVVRGDVSVIKDCKRFVOE 11 At2 gi|15241261| IGEALAYEYGKRGAYLALVDIRGEPLFHVAALAELYGSPEVLPLVADVSKLQDCERFIRA 118 At4 gi|15234888| IGEQIAYEYAKRGANLVLVARREQRLRVVSNKAKQIGANHVIIIAADVIKEDDCRRFITQ 120 Sil gi|21311775| IGEQIAYQYAKRGANLVLVARREHRLRGISENARRLGAPNVLTMAADVVKEEECRRFTNE 119

\section{Figure 4}

Sequence alignment of different short chain sterol dehydrogenases. Si: Sesamum indicum; At: Arabidopsis thaliana. The phosphopeptide is shown in red and the site of phosphorylation in bold.

\section{Enrichment of phosphoproteins using Metal Oxide Affinity} Chromatography (MOAC)

The pellet obtained by denatured protein extraction was dissolved in $1.5 \mathrm{ml}$ incubation buffer containing $30 \mathrm{mM}$ MES, $0.2 \mathrm{M}$ potassium glutamate, $0.2 \mathrm{M}$ sodium aspartate, $0.25 \%$ Chaps, and $8 \mathrm{M}$ urea with a $\mathrm{pH}$ of $6.1 .1 .5 \mathrm{ml}$ of a $0.5 \mathrm{mg} / \mathrm{ml}$ protein solution was used for $30 \mathrm{~min}$ incubation with $80 \mathrm{mg}$ of $\mathrm{AlOH}_{3}$ at $4^{\circ} \mathrm{C}\left(\mathrm{AlOH}_{3}\right.$ was washed before once with the incubation buffer described above). The incubation was followed by five washing steps of 1.6 $\mathrm{ml}$ and one step of $0.8 \mathrm{ml}$. Finally, proteins were eluted from the matrix by incubation with $800 \mu \mathrm{l}$ of $100 \mathrm{mM}$ potassium pyrophosphate buffer $\mathrm{pH} 9.0$ containing $8 \mathrm{M}$ urea for $30 \mathrm{~min}$ at RT. Proteins were precipitated with methanol/chloroform prior to gel loading as described by Wessel \& Fluegge [44] and about one half of the eluted protein fraction was loaded onto the gel.

\section{Determination of protein content}

Protein concentrations were determined via the dye-binding method of Bradford as described previously [45], using ovalbumin as a standard. Each measurement was made in triplicate and the mean values were used.

\section{SDS-PAGE, Phosphostaining, and Coomassie staining}

Pellets derived from the methanol/chloroform precipitation were dissolved in $2 \times$ SDS sample buffer $(90 \mathrm{mM}$ Tris, pH 6.9, 20\% Glycerin, 2\% SDS, 0.02\% bromophenolblue, and $100 \mathrm{mM}$ DTT) and approximately $30 \mu \mathrm{g}$ were subjected to SDS-PAGE $(800 \mu \mathrm{l}$ MOAC eluate fraction was precipitated and dissolved in $40 \mu \mathrm{l}$ of $1 \times$ SDS sample buffer). After the separation proteins were stained with Pro-Q diamond stain (Invitrogen, Karlsruhe, Germany) essentially following the instructions in the manual. For specificity, we found exchanging fixation solution once (after $30 \mathrm{~min}$ ) and leaving the gels in the fixation solution over night to be crucial steps. Phosphorylation was visualised using a chemdoc station and a $550 \mathrm{~nm}$ filter. After visualisation the phosphostain gels were washed three times with $\mathrm{ddH}_{2} \mathrm{O}$ and stained with coomassie.

\section{In-gel tryptic digest}

Seed protein spots exhibiting a strong signal after phosphostaining were excised and digested over night with trypsin as described before [46]. Peptides were extracted from the gel in three consecutive steps using increasing percentages of acetonitrile (5\%, $50 \%, 90 \%$ each containing $1 \%$ formic acid).

\section{Protein and phosphorylation site identification using nano LC-linear-iontrap-MS}

Peptides were loaded directly onto a ProteoSpher ${ }^{\circledast}$ Micro column $(0.5 \mathrm{~mm} \times 15 \mathrm{~mm})$ at a flow rate of $3 \mu \mathrm{l} / \mathrm{min}$ and separated in a 85 min gradient from $80 \% \mathrm{~A}(0.1 \%$ formic acid, and $2.5 \%$ acetonitrile in water) to $100 \% \mathrm{~B}(0.1 \%$ formic acid in methanol). Separation and measurements were performed with a nano-LC-pump (Agilent 1100) coupled to an LTQ ion trap (Thermoelectron) with a nano-ESI-source. The voltage was applied directly to the analyte solution using a T-piece. To identify tryptic peptides, phosphopeptides and phosphorylation sites, automatic data-dependent acquisition was performed consisting of a full scan (m/z 400-2000), a subsequent $\mathrm{MS}^{2}$, and a neutral loss scan of 98,49 , or $32.7\left(\mathrm{H}_{3} \mathrm{PO}_{4}\right.$ for the $+1,+2$, and +3 charged ions, respectively) in the five most abundant $\mathrm{MS}^{2}$ fragments. An $\mathrm{MS}^{3}$ scan was automatically collected on the corresponding neutral loss fragments of the MS 2 scan events. Peptides were identified by searching the spectra against an A. thaliana database http:/ /www.arabidopsis.org/ or against the C. Chlamydomonas database version 2.0 http://genome.jgi-psf.org/chlre2/ chlre2.download.html containing trypsin and keratin sequences using the Sequest algorithm (ThermoElectron, Dreieich, Germany) and filtering the results with an Xcorr of 2.0,2.5, and 3.5 for singly, doubly, and triply charged ions, respectively. Protein hits were accepted when at least three peptides with the corresponding Xcorr criteria described above were identified. The spectra derived from phosphopeptides were verified manually (charge state and identification of $\mathrm{MS}^{2}$ and $\mathrm{MS}^{3}$ spectra were checked for their concordance).

\section{Sequence alignment}

Sequences were derived from NCBI http:// www.ncbi.nlm.nih.gov/entrez/query.fcgi?db=Protein and alignment was performed using ClustalW http:// www.ebi.ac.uk/clustalw/ with the default settings.

\section{Authors' contributions}

FW carried out the optimization of MOAC with seed material, phosphorylation site identification using $\mathrm{MS}^{2}$ and $\mathrm{MS}^{3}$ and participated in writing and drafting the manuscript. WW drafted the conception of this study, advised throughout the project and participated in writing and drafting the manuscript. 


\section{Acknowledgements}

We thank Megan McKenzie for revising the manuscript. We thank the Max Planck Society for financial support and Mirko Glinski, Stefanie Wienkoop, and Mark Stitt for valuable discussion. Finally, we thank Daniel Karcher, Dietrich Köster, and Christian Bölling for providing C. reinhardtii, Regina Stark and Karsten Oelkers for technical assistance.

\section{References}

I. Agrawal GK, Yonekura M, Iwahashi Y, Iwahashi H, Rakwal R: System, trends and perspectives of proteomics in dicot plants Part II: Proteomes of the complex developmental stages. J Chromatogr B Analyt Technol Biomed Life Sci 2005, 815:125-136.

2. Rubin CS, Rosen OM: Protein phosphorylation. Annu Rev Biochem 1975, 44:83 I-887.

3. Ma H: Protein phosphorylation in plants: enzymes, substrates and regulators. Trends Genet 1993, 9:228-230.

4. Glinski M, Weckwerth W: The Role of Mass Spectrometry in Plant Biology. Mass Spectrometry Reviews 2005, in press:.

5. Glinski M, Romeis T, Witte CP, Wienkoop S, Weckwerth W: Stable isotope labeling of phosphopeptides for multiparallel kinase target analysis and identification of phosphorylation sites. Rapid Commun Mass Spectrom 2003, I 7:1579-I584.

6. Glinski M, Weckwerth W: Differential Multisite Phosphorylation of the Trehalose-6-phosphate Synthase Gene Family in Arabidopsis thaliana: A Mass Spectrometry-based Process for Multiparallel Peptide Library Phosphorylation Analysis. Mol Cell Proteomics 2005, 4: 1614-1625.

7. Martin K, Steinberg TH, Goodman T, Schulenberg B, Kilgore JA, Gee KR, Beechem JM, Patton WF: Strategies and solid-phase formats for the analysis of protein and peptide phosphorylation employing a novel fluorescent phosphorylation sensor dye. Comb Chem High Throughput Screen 2003, 6:331-339.

8. Schulenberg B, Goodman TN, Aggeler R, Capaldi RA, Patton WF: Characterization of dynamic and steady-state protein phosphorylation using a fluorescent phosphoprotein gel stain and mass spectrometry. Electrophoresis 2004, 25:2526-2532.

9. Schulenberg B, Arnold B, Patton WF: An improved mechanically durable electrophoresis gel matrix that is fully compatible with fluorescence-based protein detection technologies. Proteomics 2003, 3: I I 96-1205.

10. Steinberg TH, Agnew BJ, Gee KR, Leung WY, Goodman T, Schulenberg B, Hendrickson J, Beechem JM, Haugland RP, Patton WF: Global quantitative phosphoprotein analysis using Multiplexed Proteomics technology. Proteomics 2003, 3: I I 28- I I 44.

II. Goodman T, Schulenberg B, Steinberg TH, Patton WF: Detection of phosphoproteins on electroblot membranes using a smallmolecule organic fluorophore. Electrophoresis 2004, 25:2533-2538.

12. Salih E: Phosphoproteomics by mass spectrometry and classical protein chemistry approaches. Mass Spectrom Rev 2004:DOI 10.1002/mas.20042.

13. Zeller M, Konig S: The impact of chromatography and mass spectrometry on the analysis of protein phosphorylation sites. Anal Bioanal Chem 2004, 378:898-909.

14. Laugesen S, Bergoin A, Rossignol M: Deciphering the plant phosphoproteome: tools and strategies for a challenging task. Plant Physiol Biochem 2004, 42:929-936.

15. Nuhse TS, Stensballe A, Jensen ON, Peck SC: Phosphoproteomics of the Arabidopsis plasma membrane and a new phosphorylation site database. Plant Cell 2004, I 6:2394-2405.

16. Aro EM, Rokka A, Vener AV: Determination of phosphoproteins in higher plant thylakoids. Methods Mol Biol 2004, 274:27 I-285.

17. Heintz D, Wurtz V, High AA, Van Dorsselaer A, Reski R, Sarnighausen E: An efficient protocol for the identification of protein phosphorylation in a seedless plant, sensitive enough to detect members of signalling cascades. Electrophoresis 2004, 25: I| 49 - I I59.

18. Wolschin F, Wienkoop S, Weckwerth W: Enrichment of phosphorylated proteins and peptides from complex mixtures using metal oxide/hydroxide affinity chromatography (MOAC). Proteomics 2005, [Epub ahead of print]:

19. Weckwerth W, Willmitzer L, Fiehn O: Comparative quantification and identification of phosphoproteins using stable isotope labeling and liquid chromatography/mass spectrometry. Rapid Communications in Mass Spectrometry 2000 , |4:1677-|68I.

20. Jaffe H, Veeranna, Pant HC: Characterization of serine and threonine phosphorylation sites in beta-elimination/ethanethiol addition-modified proteins by electrospray tandem mass spectrometry and database searching. Biochemistry 1998, 37: $16211-16224$

21. McLachlin DT, Chait BT: Improved beta-elimination-based affinity purification strategy for enrichment of phosphopeptides. Anal Chem 2003, 75:6826-6836.

22. Goshe MB, Conrads TP, Panisko EA, Angell NH, Veenstra TD, Smith RD: Phosphoprotein isotope-coded affinity tag approach for isolating and quantitating phosphopeptides in proteomewide analyses. Anal Chem 200I, 73:2578-2586.

23. Klemm C, Schroder S, Gluckmann M, Beyermann M, Krause E: Derivatization of phosphorylated peptides with $\mathbf{S}$ - and $\mathbf{N}$-nucleophiles for enhanced ionization efficiency in matrix-assisted laser desorption/ionization mass spectrometry. Rapid Communications in Mass Spectrometry 2004, I 8:2697-2705.

24. Syka JE, Coon JJ, Schroeder MJ, Shabanowitz J, Hunt DF: Peptide and protein sequence analysis by electron transfer dissociation mass spectrometry. Proc Natl Acad Sci U S A 2004, I 0 I:9528-9533.

25. DeGnore JP, Qin J: Fragmentation of phosphopeptides in an ion trap mass spectrometer. J Am Soc Mass Spectrom 1998, 9: $1175-1188$

26. Olsen JV, Mann M: Improved peptide identification in proteomics by two consecutive stages of mass spectrometric fragmentation. Proc Natl Acad Sci U S A 2004, I 0 I: 1 34 I7-1 3422.

27. Giorgianni F, Beranova-Giorgianni S, Desiderio DM: Identification and characterization of phosphorylated proteins in the human pituitary. Proteomics 2004, 4:587-598.

28. Jin WH, Dai J, Zhou H, Xia QC, Zou HF, Zeng R: Phosphoproteome analysis of mouse liver using immobilized metal affinity purification and linear ion trap mass spectrometry. Rapid Commun Mass Spectrom 2004, I 8:2169-2176.

29. Shu H, Chen S, Bi Q, Mumby M, Brekken DL: Identification of phosphoproteins and their phosphorylation sites in the WEHI-23 I B lymphoma cell line. Mol Cell Proteomics 2004, 3:279-286.

30. Medzihradszky KF, Darula Z, Perlson E, Fainzilber M, Chalkley RJ, Ball H, Greenbaum D, Bogyo M, Tyson DR, Bradshaw RA, Burlingame AL: O-sulfonation of serine and threonine: mass spectrometric detection and characterization of a new posttranslational modification in diverse proteins throughout the eukaryotes. Mol Cell Proteomics 2004, 3:429-440.

31. Lin LJ, Tzen JT: Two distinct steroleosins are present in seed oil bodies. Plant Physiol Biochem 2004, 42:601-608.

32. Wolschin F, Lehmann U, Glinski M, Weckwerth. W: An integrated strategy for identification and relative quantification of sitespecific protein phosphorylation using liquid chromatography coupled to MS2/MS3. Rapid Commun Mass Spectrom 2005, in press:.

33. Borisjuk L, Rolletschek $H$, Radchuk R, Weschke W, Wobus $U$ Weber H: Seed development and differentiation: A role for metabolic regulation. Plant Biology 2004, 6:375-386.

34. Walker-Simmons MK: Protein kinases in seeds. Seed Science Research 1998, 8:193-200.

35. Wysocki VH, Tsaprailis G, Smith LL, Breci LA: Mobile and localized protons: a framework for understanding peptide dissociation. J Mass Spectrom 2000, 35:| 399-|406.

36. Salek M, Di Bartolo V, Cittaro D, Borsotti D, Wei J, Acuto O, Rappsilber J, Lehmann WD: Sequence tag scanning: a new explorative strategy for recognition of unexpected protein alterations by nanoelectrospray ionization-tandem mass spectrometry. Proteomics 2005, 5:667-674.

37. Samaj J, Baluska F, Hirt H: From signal to cell polarity: mitogenactivated protein kinases as sensors and effectors of cytoskeleton dynamicity. J Exp Bot 2004, 55:189-198.

38. Schmid M, Davison TS, Henz SR, Pape UJ, Demar M, Vingron M, Scholkopf B, Weigel D, Lohmann JU: A gene expression map of Arabidopsis thaliana development. Nat Genet 2005, 37:501-506.

39. Weckwerth W, Selbig J: Scoring and identifying organism-specific functional patterns and putative phosphorylation sites in protein sequences using mutual information. Biochem Bioph Res Co Biochem Bioph Res Co 2003, 307:516-521. 
40. Rodriguez-Gabriel MA, Bou G, Briones E, Zambrano R, Remacha M, Ballesta JP: Structure and function of the stalk, a putative regulatory element of the yeast ribosome. Role of stalk protein phosphorylation. Folia Microbiol (Praha) 1999, 44:153-163.

41. Nusspaumer G, Remacha M, Ballesta JP: Phosphorylation and Nterminal region of yeast ribosomal protein $\mathrm{PI}$ mediate its degradation, which is prevented by protein P2. Embo J 2000, 19:6075-6084

42. Lin LJ, Tai SS, Peng CC, Tzen JT: Steroleosin, a sterol-binding dehydrogenase in seed oil bodies. Plant Physiol 2002, 128: $|200-| 2||$.

43. Harris EH: The Chlamydomonas Sourcebook. Academic Press, Inc, San Diego, CA, USA 1989.

44. Wessel $D$, Flugge UI: $A$ method for the quantitative recovery of protein in dilute solution in the presence of detergents and lipids. Anal Biochem 1984, 138: |41-143.

45. Bradford MM: Rapid and Sensitive Method for Quantitation of Microgram Quantities of Protein Utilizing Principle of Protein-Dye Binding. Analytical Biochemistry 1976, 72:248-254.

46. Otto A, Thiede B, Muller EC, Scheler C, WittmannLiebold B, Jungblut $P$ : Identification of human myocardial proteins separated by two-dimensional electrophoresis using an effective sample preparation for mass spectrometry. Electrophoresis 1996, 17:1643-1650. 